\section{The Indo-Pacific Loggerhead Turtle in Tasmanian Waters}

There appears to be only one published record of a chelonian in Tasmania ${ }^{1}$, that of a leathery turtle, Dermochelys coriacea (Linné, 1766), which came ashore at Fortescue Bay in March 1889 (specimen in Tasmanian Museum, Hobart). From unpublished information supplied by Mr. John Fazackerly, it seems probable a large turtle observed by him to emerge from the sca at this locality in or about 1945 was a second example of this species.

We are now able to present reports of the appearance, within the past five years, of no fewer than eleven other turtles on the cousts of Tasmaniathree entries being based on available specimens or parts thereof, the remainder on hearsay only. Material examinod comprises: (1) skull of the first animal to come under our notice, a fairly fresh example found stranded by one of us (B. C. M.) about half a mile north of Mount Cameron West on November 24, 1951; (2) skull and greator part of the carapace from near the mouth of the Arthur River (Mr. Bailey, per Mr. M. Olsen, probably November 1951); (3) complete young animal from Adventure Bay, Bruny Island (Tasmanian Museum, Hobart, August 24, 1955). These have been determined as the Indo-Pacific red-brown loggerhead, Caretta caretta gigas Deraniyagala, 1933. Reports, unsupported by material, but thought probably to be this species (or this species and the green turtle ?) comprise: (4-7) four individuals stranded at Stud. land Bay (Mr. G. Wainwright, about September 195I); (8) one swimming near Stanley (Mr. M. Hardy, 1951); (9) one stranded at Port Davey (Mr. C. Clayton, February or March, 1940); (10) one stranded near the mouth of the Arthur River (Mr. Bailey, date unknown) ; (11) one stranded at Currie, King Island (Mr. R. Clarke, 1951).

A paper dealing directly with the records enumerated above will appear in Vol. 90 of the Papers and Proceedings of the Royal Society of Tasmania; and it is hoped a further study of some of the problems raised by an examination of the material will later be published elsewhere.

\section{Launceston.}

$$
\text { E. O. G. ScotT }
$$

Hobart.

1 Lord, C. E., and Scott, H. If. " A Synopsis of the Vertebrate Animals of Tasmania" (Oldham, Beddome and Meredith, Hobart, 1924).

\section{Extraneous X-Ray Diffraction Patterns from Algal Flagella}

Ww should like to sound a warning that might save other workers in this new and difficult field from some of the troubles that have beset our own investigations. Our aim has been to obtain X-ray diffraction diagrams of oriented preparations of the flagella of alg $x e$, sperm, etc., of a standard comparable with those already obtained with bacterial flagella ${ }^{1}$, and it was in fact believed that an encouraging advance towards this end had been achieved a few years ago ${ }^{2}$. Now, however, it has become apparent that it is much easier to discover diagrams of metabolic by-products and various other artefacts than of the flagella substance proper.

For example, flagella prepared from Polytoma grown in yeast/acetate/'Bacto-tryptone'/distilled water give a clean though non-specific protein diagram (diffuse, disoriented 'side-chain' and 'backbone' reflexions); but if tap water is used instead-and Leeds water is quite soft-then the protein diagram is lost in a strong pattern of an apatite type, to judge by its resemblance to patterns given by bone and dentine. The effect was finally tracked down to the intervention not of tap water alone but of tap water plus 'Bacto-tryptone'; but it was found that the pattern was given also by the lighter, more flocculent fraction of the precipitate formed when a distilledwater solution of 'Bacto-tryptone' was treated with $0 \cdot 1 M$ ammonia. In the electron microscope this precipitate seemed amorphous, but electron micrographs of the flagella which gave the apatite-type Xray pattern showed them to be crusted over with hexagonal-looking platelets--built up more slowly, of course, and under the conditions generated by the growing flagella. These conditions are known to bring the $p \mathrm{H}$ up to about 9 , but evidently some contribution from the tap water is involved too.

Probably these results mean nothing more than that growing organisms produce things other than themselves, and that one must therefore watch with especial care in pioneer X-ray studies of this kind; but they could conceivably be pointing to something much more significant, for the artefact here is a by-product of organisms growing on constituents which include 'Bacto-tryptone', a pancreatic digest of casein; and it may be that the 'bone-like' nature of the pattern really is an expression of a remote relationship with large-scale biological apatite formation in multicellular creatures.

In any event, a more immediately important consequence has been the realization that it must have been 'Bacto-tryptone', too, that was ultimately responsible for the X-ray pattern we thought ${ }^{2}$ came from the actual flagella of Polytoma, etc. It is clear now that this pattern was not authentic, but was of a metabolic by-product trapped in, or adhering to, the flagellar structure. Because of the difficulty of reproducing exactly the conditions and materials of the earlier experiments it is not certain exactly how, but the fact remains that a roughly similar pattern is given by fresh 'Bacto-tryptone', and a very similar pattern by what is left when the supernatant from an algal culture has been evaporated to dryness.

W. T. Astrunt F. G. E. Pautard

Department of Biomolecular Structure,

University of Leeds. June 12.

${ }^{1}$ Astbury, W. T., and Weibull, C., Nature, 163, 280 (1949). Astbury W. T., Beighton, E., and Weibull, C., Soc. Exp. Biol., Symp., 9, 282 (i955).

${ }^{2}$ Astbury, W. T., and Saha, N. N., Nature, 171, 280 (1953).

\section{Sterculic Acid and its Halphen Reaction}

THE structure of sterculic acid has recently been confirmed in this laboratory ${ }^{1}$ as (I), proposed by Nunn $^{2}$, rather than as (II), suggested by Verma, Nath and Aggarwal ${ }^{3}$.

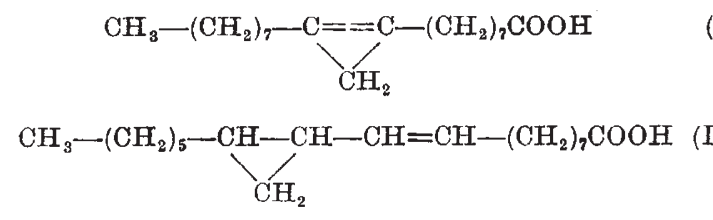

This investigation revealed a band at $\mathbf{5} \cdot \mathbf{3 5} \mu$ in the spectrum of fresh sterculic acid, which is believed to 